\title{
De la ontología al arte. Los caminos medievales de la belleza
}

\author{
From Ontology to Art: the medieval ways of Beauty
}

Fr. Luis Javier García-Lomas Gago OSB

Abadía Benedictina de Santo Domingo de Silos

fr.luisjavier@gmail.com

\begin{abstract}
Resumen: El presente artículo pretende rastrear los caminos por los que la noción de belleza ha transitado durante el pensamiento medieval, identificando dos grandes líneas de pensamiento: la belleza ontológica y la belleza formal. Ambos vienen a coincidir en la reflexión de Tomás de Aquino, cuya mirada abrirá el camino hacia una reflexión más autónoma del arte.
\end{abstract}

Palabras claves: belleza, ontología, forma, autonomía, participación, arte.

\begin{abstract}
This paper seeks to find the roots of the medieval idea of Beauty. It does so by identifying two main currents of thought concerning Beauty: beauty as ontology and beauty as form. They both concur in Aquinas' thought, whose views will open the way for a more autonomous ways of thinking about art.
\end{abstract}

Keywords: beauty, ontology, form, autonomy, participation, art.

\section{INTRODUCCIÓN: PROPÓSITO Y METODOLOGÍA DE ESTUDIO}

En las páginas que siguen ${ }^{1}$ pretendemos adentrarnos en la consideración que la noción de "belleza" ha tenido en el pensamiento occidental, principalmente durante la Edad Media. El concepto de "belleza", asociado comúnmente a lo sensible, a lo que perciben los sentidos (y, por ende, al arte que se manifiesta a los sentidos del hombre), sufre una reorientación durante la Edad Media al ubicarse la fuente de toda belleza en la divinidad, en el Dios cristiano. Así, los supuestos básicos de la filosofía platónica se van a combinar con la revelación cristiana de una forma simbiótica, generando una cosmovisión donde toda belleza sensible lo es por su participación de la Suma Belleza. Esta visión

1 Este trabajo se inserta en un camino de investigación suscitado por el prof. D. Jordi Claramonte Arrufat, de la Universidad Nacional de Educación a Distancia, a quien desde aquí queremos agradecer su apoyo y consejo. 
va a impregnar la concepción de la esencia y función del arte, como veremos en pensadores como Suger de Saint Denis.

Pretendemos investigar el desarrollo de esta ontologización de la belleza durante la Edad Media, haciendo un recorrido somero por autores clave como el Pseudo-Dionisio, Escoto Eriúgena y el innominado autor de la Summa Fratris Alexandri, que llevará la ontologización de la belleza al máximo al afirmar que todo lo que participa del ser es bello por el mero hecho de ser.

Por otro lado, en la plenitud de la Edad Media, la recuperación de Aristóteles y de una concepción más naturalista del mundo van a contribuir al desarrollo de una noción de belleza más apegada a lo sensible por parte de Santo Tomás de Aquino, noción que contrastará con la belleza hipostasiada, casi personalizada, de tradición platónica y que servirá de contrapeso a la misma, dando inicio (a nuestro juicio) al lento proceso de conquista de la autonomía del arte al irlo desvinculando de supuestos metafísicos previos.

Esta noción de Santo Tomás va a ser el resultado de una concepción que denominaremos "estética" o "formal" de la belleza que, aunque de forma menos acentuada que la belleza metafísica, va a desarrollarse en el pensamiento medieval, particularmente en San Agustín. Se trata de una noción que pone el acento en el orden y la armonía de lo percibido por los sentidos. Concluiremos el estudio con una reflexión personal sobre la relevancia que esta evolución puede tener hoy para quien se sigue preguntando por el arte y por una noción aparentemente tan denostada como la"belleza".

Antes de dar inicio a nuestro estudio, una nota sobre metodología se hace necesaria. Este pretende ser un estudio de fuentes, es decir, un estudio de las obras o textos de los autores que reflexionaron sobre la belleza y su relación con Dios y con los seres respectivamente. Así, en cada uno de los apartados iremos citando textos ${ }^{2}$ y comentándolos para mostrar su lugar en la evolución de las ideas estéticas que estamos trazando.

De esta manera, intentaremos recurrir lo mínimo a la literatura secundaria. Grandes investigadores como U. Eco o W. Tatarkiewicz han escrito sobre estos temas con una profundidad que nosotros no esperamos alcanzar en nuestro estudio. Con todo, el recurso directo a los textos permite obviar el prejuicio de leer dichos textos con las "gafas" de quienes han investigado sobre los mismos. No pretendemos llegar a conclusiones novedosas o rompedoras. Solo queremos dar voz a Platón, al

2 Citaremos los textos en su idioma original cuando la dicción original (latina o griega) tenga relevancia en nuestro estudio. 
Pseudo-Dionisio y a tantos otros que ya se preguntaron por la causa de que podamos llamar "bello" a algo. Estimamos que lo que nos digan no carecerá de interés, y así pretendemos ponerlo de manifiesto al terminar nuestro estudio con unas consideraciones sobre la posible actualidad del pensamiento medieval sobre la belleza.

Antes de comenzar, conviene hacer una precisión terminológica. En este estudio vamos a tratar fundamentalmente de la belleza en su consideración más abstracta, es decir, como una propiedad que es posible adscribir a los entes, artísticos o no artísticos. Es la perspectiva que adoptaron la mayor parte de los autores medievales, y es lo que hemos llamado "ontologización" de la belleza. Nosotros, con la herencia filosófica de la Ilustración y el Romanticismo a cuestas, asociamos arte y belleza habitualmente de forma automática. Para los autores medievales, la relación es más compleja. Por eso el título del estudio: de la ontología al arte. Ese es el camino que va a recorrer la noción de belleza a lo largo de los siglos.

\section{PRIMERA PARTE: La Belleza ontológica}

\subsection{Conceptos básicos: Platón y su posteridad filosófica}

El camino que pretendemos trazar en estas páginas solo puede comprenderse si, antes de iniciarlo en los albores de la Edad Media con el Pseudo Dionisio, nos remontamos a los presupuestos filosóficos que configuraron el pensamiento occidental durante los primeros siglos de la Edad Media: la metafísica platónica y los supuestos filosóficos contenidos en la revelación cristiana. Solo partiendo de aquí podremos comprender cómo la noción de belleza acabó englobada dentro del ámbito de la ontología, de la reflexión sobre el ser.

Hasta la recuperación de Aristóteles en el siglo XIII, la filosofía medieval era fundamentalmente platonismo cristianizado que asumía como herramienta interpretativa un conjunto de verdades derivadas de la metafísica platónica. Pues bien, en algunos de sus diálogos, Platón expresa la posibilidad de acceso a este mundo de las esencias o mundo de las ideas por caminos no estrictamente dialécticos. Así, frente al camino ascensional que diseña en diálogos como República, en Banquete y en Fedro aparece la belleza de las cosas como un camino de ascenso a las ideas, concretamente a la idea de Belleza, ascenso que se realiza por medio del amor, de Eros.

En Banquete, Eros es un demon, no un dios, es decir, es una fuerza intermedia entre los dioses y los hombres. Su función es la de servir de mediador entre ambos, uniendo ambos mundos. Se trata por tanto de una fuerza dinámica y sintética, mediadora de los opuestos, del mundo 
de las ideas y de la realidad de los sentidos. En este sentido metafísico, Eros es por tanto la fuerza que anima la búsqueda y fruición del Bien que tiene lugar mediante la contemplación de la belleza. Por eso se define a Eros no como algo bello, sino como amor a la belleza y al mismo tiempo deseo de poseer el Bien (206b), de disfrutarlo de forma permanente. Pero mucho más interesante para nosotros es la caracterización que de Eros se hace en Fedro:

Y aquí es, precisamente, a donde viene a parar todo ese discurso sobre la cuarta forma de locura, aquella que se da cuando alguien contempla la belleza de este mundo, y, recordando la verdadera, le salen alas y, así alado, le entran deseos de alzar el vuelo, y no lográndolo, mira hacia arriba como si fuera un pájaro. Olvidado de las de aquí abajo. y dando ocasión a que se le tenga por loco. Así que, de todas las formas de "entusiasmo", es esta la mejor de las mejores, tanto para el que la tiene, como para el que con ella se comunica; y al partícipe de esta manía, al amante de los bellos, se le llama enamorado. ${ }^{3}$

Fedro viene a completar la comprensión de Eros que acabamos de exponer. En este diálogo, Eros no se concibe hipostasiado en un personaje, el demon al que antes hemos aludido. Aquí Eros aparece como una fuerza, un impulso que lleva al alma a ascender desde lo bello sensible hasta lo bello inteligible, impulso que viene a ser comparado con una locura o, como ya hemos dicho, con las "alas" que el alma posee para poder elevarse hacia la contemplación de las Ideas. Eros se convierte así, en palabras de E. Lledó, en:

una forma de superación de los límites de la carne y del deseo, una salida a otro universo en el que amar es ver y en el que desear es entender. Por ello ese "poder natural del ala" que nos alza por encima de la dóxa nos lleva a la ciencia del ser, a "esa ciencia que es de lo que verdaderamente es ser" (247d). La teología y ontología expuestas por Platón van entrelazadas con uno de sus más espléndidos mitos en donde sus personajes son el alma y el mundo de las ideas, los símbolos que plasman, en sus dioses, los sueños de los hombres, las contradicciones entre el egoísmo y la entrega, entre la pasión y la razón. ${ }^{4}$

De esta forma, podemos comprobar como al caracterizar a Eros como fuerza ascensional, la belleza de lo sensible viene, al mismo tiempo, definida y devaluada. Definida pues se la contempla como un locus ascensionalis, si se nos permite el neologismo: un ámbito de ascenso. Devaluada porque, de acuerdo con la ontología platónica, carece de valor intrínseco. De la misma manera, en Banquete 210a-212c, aparece descrito

3 Fedro, 249d-249e, trad. de E. Lledó Íñigo en Platón, Diálogos III, (Biblioteca Clásica Gredos 93), Madrid, Gredos, 1986.

4 Emilio Lledó ÍñIgo, Introducción a Fedro en Platón, Diálogos III, 299. 
el camino desde la belleza sensible a la contemplación y fruición de lo Bello en sí, o si se prefiere, de la Idea de Belleza. Esta ascensión aparece descrita en cinco grados o peldaños:

1. Amor a la belleza de los cuerpos, es decir, la emoción que produce la visión y la fruición de la belleza física.

2. Amor a la belleza de un alma, que es la verdadera belleza de un hombre (nueva devaluación de lo sensible). Este amor lleva al deseo de que el alma crezca en la virtud.

3. Amor a la belleza de las actividades y de las leyes humanas: armonía y justicia.

4. Amor a la belleza de las ciencias: orden, simetría y definición son aspectos fundamentales a la hora de contemplar lo Bello, por lo que es necesario, en el camino ascensional, contemplar estas ciencias como algo bello.

5.Visión de lo Bello manifestado en sí mismo, es decir, de la Idea de Belleza.

Este es el camino descrito por Platón en Banquete. Por medio de él es posible pasar de la contemplación amorosa de la belleza sensible a la fruición de la Belleza en sí. El resultado de esta contemplación aparece descrito en términos no solo hermosos, sino de importantes resonancias místicas y éticas. Así, dirá Diótima a Sócrates: ¿Acaso crees — dijo— que es vana la vida de un hombre que mira en esa dirección, que contempla esa belleza con lo que es necesario contemplarla y vive en su compañía?" (212a).

De lo anteriormente expuesto podemos retener para el resto de nuestro estudio que Platón pone la primera piedra del edificio conceptual que iremos describiendo al concebir la belleza del mundo sensible (natural y artística) como un ámbito donde ascender a una Belleza hipostasiada, una Belleza metafísica que, como veremos, tiene mucha relación con la noción de Sumo Bien. ${ }^{5}$ Con ello, las cuestiones que hoy llamaríamos estéticas quedan relegadas a un segundo plano en favor de

5 Resulta en este sentido muy revelador este paso del Filebo:

"SOC.: Resulta, pues, que la potencia del bien se nos ha refugiado en la naturaleza de lo bello; en efecto, la medida y la proporción coinciden en todas partes con belleza y perfección.

PRO.: Totalmente.

SOC.: De hecho, declamas que la verdad se une a ellas en la mezcla.

PRO.:Y tanto.

SOC.: Entonces, si no podemos capturar el bien bajo una sola forma, tomémoslo en tres, belleza, proporción y verdad, y digamos que con todo derecho podemos atribuir a esta sola unidad el ser causa de las cualidades de la mezcla, y que, por ella, porque es buena, la mezcla resulta ser tal." Filebo 64e-65a, trad. de Mǻngeles Durán en PLATÓN, Diálogos VI, (Biblioteca Clásica Gredos 160), Madrid, Gredos, 1992. 
una ontologización de la belleza. La importancia concedida a la Suprema Belleza, la belleza metafísica, hace de Platón el padre de las pankalías, es decir, de aquellas concepciones de la belleza que la ven como una propiedad de todos los entes.

\subsection{La síntesis platónico-cristiana del Pseudo-Dionisio}

\subsubsection{Nociones filosóficas aportadas por el cristianismo al pensamiento occidental}

Antes de entrar en el estudio del capítulo IV del De Divinis Nominibus hemos de hacer una breve referencia a los presupuestos filosóficos que la aparición del Cristianismo aporta a la historia del pensamiento de tal forma que, combinados con lo que ya hemos expuesto sobre Platón, expliquen el enfoque que van a adoptar el Pseudo-Dionisio en relación con la belleza. Siendo esta una cuestión compleja que excede el propósito de este estudio, nos limitamos a recoger sumariamente los aspectos más importantes de la revelación cristiana desde un punto de vista filosófico: ${ }^{6}$

I. En primer lugar, el cristianismo, heredero del judaísmo, afirma la existencia de un único Dios creador. De ahí se sigue una metafísica creacionista que innova frente a las cosmologías platónica y aristotélica al afirmar la creatio ex nihilo. ${ }^{7}$ Dios crea, de la nada, todas las cosas. Es por tanto la fuente del ser.

II. Asimismo, la metafísica creacionista implica una concepción lineal-escatológica del tiempo frente a la concepción cíclica propia del mundo griego. Así, Dios es creador de todas las cosas (causa eficiente) y al mismo tiempo todas las cosas van hacia Dios (causa final), en quien se consuma la historia.

III. El Dios cristiano es concebido como una entidad personal, dotada de inteligencia y de voluntad. Providente y bondadoso, el cristianismo dirá que su esencia es ser Amor (1 Jn 4, 8:"Quien no ama no ha conocido a Dios, porque Dios es amor").

IV. La benevolencia de Dios se manifiesta en dos momentos: creación y redención. En la primera, tal y como presenta a Dios la relectura del relato del Génesis que hace el libro de la Sabiduría, la bondad de Dios es la que le impulsa a crear el mundo y al hombre, pero esta creación no es arbitraria ni caótica, sino que obedece a un diseño armónico, como expresa Sab 11, 20: "pero tú todo lo has dispuesto con peso, número y medida".

V. Finalmente, la revelación bíblica afirma expresamente la posibilidad de acceder a Dios a través de la contemplación de la belleza de las cosas sensibles en el

6 Seguimos aquí a Emerich CORETH, Dios en la Historia del pensamiento filosófico, Salamanca, Sígueme, 2016, 81ss.

7 Ya apuntada por el medioplatonismo y por Filón pero no explícitamente concebida hasta los padres de la Iglesia. Cf: Javier GARCíA-LOMAS GAGO, “De Atenas a Jerusalén: La creación del mundo en Filón del Alejandría", Isidorianum 54 (2018) 1-14. 
mismo libro de la Sabiduría, que afirma que"por la grandeza y hermosura de las

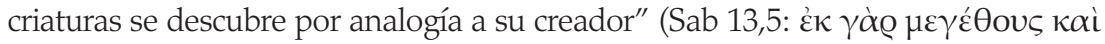

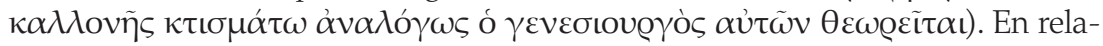
ción con este último aspecto, resulta muy interesante el desplazamiento semántico que se produce cuando la Biblia Hebrea es traducida al griego en Alejandría para los judíos de la diáspora. La célebre traducción de los Setenta, que es la versión de la Escritura que usaron los autores del Nuevo Testamento, traduce la conocida

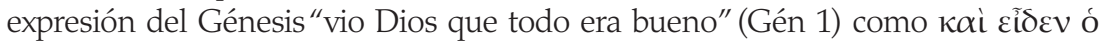

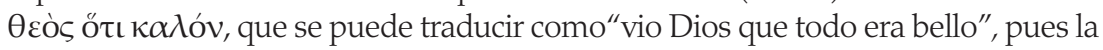
palabra $\kappa \alpha \lambda$ ós, además de bueno, significa bello. Este hecho apunta a algo que va a resultar clave en el Pseudo-Dionisio y en toda la estética del platonismo cristiano: la identificación entre Bien y Belleza, identificación que durará al menos hasta Santo Tomás. Algo que ya estaba in nuce en Platón, se va a ver confirmado por la revelación bíblica, con las consecuencias que iremos detallando a continuación.

VI. Este texto, de gran relevancia, encuentra su paralelo en el Nuevo Testamento en la Carta a los Romanos. En ella San Pablo, recogiendo la doctrina de la analogía, afirma lo siguiente: "pues lo invisible de Dios, su eterno poder y su divinidad, son perceptibles para la inteligencia a partir de la creación del mun-

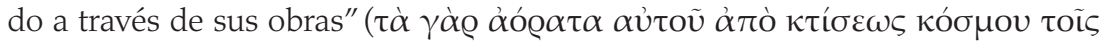

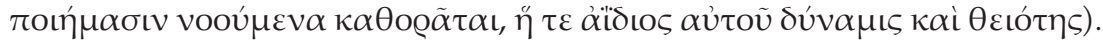
La tradición que había inaugurado Platón del mundo sensible como camino hacia la realidad verdadera aparece aquí confirmada por la revelación bíblica.

Así pues, la cosmovisión cristiana ve el mundo como obra de un Dios personal, providente y amante del hombre de quien proviene toda la creación y hacia quien camina dicha creación. La creación misma es vista desde este punto de vista como teofánica, es decir, como una manifestación de ese Dios providente y como un medio para llegar a Él. Este Dios, como fuente del ser, se va a convertir, como veremos, en la fuente de toda belleza y en la Belleza misma, y de ahí derivará la asunción por parte del cristianismo de la noción de pankalía, en tanto que todo es bello por ser obra de la Belleza suprema que es Dios.

\subsubsection{El capítulo IV del De Divinis Nominibus: ${ }^{8}$ la belleza supersubstancial}

Resulta cuanto menos curioso que un personaje tan importante en la historia del pensamiento haya quedado en el anonimato. En efecto, el autor que conocemos hoy como Pseudo-Dionisio escribió sus obras bajo

8 En todas nuestras referencias a esta obra seguiremos la versión bilingüe griegofrancés publicada por la colección Sources Chrétiennes: Ps. Denys L'ARÉOPAgrte, Les Noms Divins I-IV, Introduction, traduction et notes par Ysabel de Andia (Sources Chrétiennes 578), Paris, Cerf, 2016. 
el pseudónimo de Dionisio Areopagita, uno de los primeros convertidos al cristianismo por San Pablo en la ciudad de Atenas según el libro de los Hechos de los Apóstoles (Hch 17, 34). Aunque durante siglos fue tenido por tal, el conocimiento que revela de las obras del último platonismo ateniense (Proclo y Damascio) lo sitúa en el sigloV. Las últimas hipótesis apuntan a un monje sirio con amplios conocimientos filosóficos. ${ }^{9}$

Como el mismo nombre de la obra implica, De Divinis Nominibus trata sobre los nombres de Dios. ${ }^{10} \mathrm{El}$ Dios que se revela sin dar su nombre $($ Éx 3,14$)$ es llamado de muchas formas en la Biblia. Para Dionisio, cada una de estas formas dice algo de Dios a pesar de que, como afirma en el

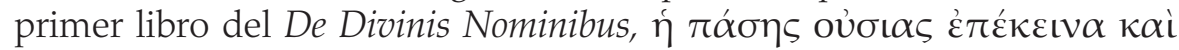

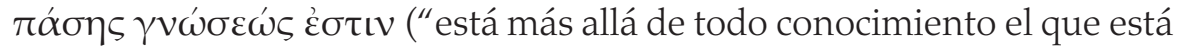
más allá de toda esencia"11), afirmación llena de resonancias platónicas. Pero a pesar de esta incognoscibilidad aparente de Dios (y aquí es donde entra en juego la belleza), podemos hablar de Dios por que es causa de todas las cosas. Dios está más allá del ser y del conocimiento pero es la causa de todo, por lo que podemos conocer a Dios por sus efectos en el mundo. En este sentido se va a desarrollar De Divinis Nominibus, cuyo capítulo cuarto nos va a resultar de sumo interés.

En el mencionado capítulo IV, el autor se refiere a Dios con dos nombres que ya hemos visto están muy relacionados: Bien y Belleza. Aunando las tradiciones platónica y cristiana, Dios aparece reuniendo en sí ambas cualidades en grado sumo (o como dirá Santo Tomás, supereminente). Así, si Dios es la Belleza en grado sumo y Dios es causa de todas las cosas, la belleza de todas las cosas es por el hecho de venir de Dios. Al mismo tiempo, los entes sensibles aparecen como manifestaciones de la belleza de Dios, como teofanías que revelan a Dios y su presencia en los entes. Profundamente vinculado a esto está la dinámica erótico-ascensional por la cual la belleza se convierte en un camino de ascenso a Dios por medio del amor.

Sintetizado así el contenido del capítulo IV 1-7, que es la parte que nos interesa de dicho capítulo, vamos a ir desgranando con los textos las ideas principales del mismo. Podemos distinguir dos partes: IV 1-5, donde Dios aparece identificado con el Sumo Bien, y IV 6-7 donde aparece Dios como Suma Belleza o Belleza supersubstancial. Si bien nuestro

\footnotetext{
9 Es la conclusión a la que llega Ysabel De Andia en su introducción a De Divinis Nominibus que hemos citado en la nota anterior, p. 10.

10 Seguimos aquí a Erich Perl, Pseudo-Dyonisius the Areopagite, en Lloyd P. Gerson (ed.), The Cambridge History of Philosophy in Late Antiquity, Cambridge, Cambridge University Press, 2011, 767ss.

11 De Divinis Nominibus I, 4, 60.
} 
interés se centra en lo segundo, no podemos entenderlo sin hacer referencia a la primera parte. En ella, Dios aparece como la fuente de todo bien en un doble movimiento de descenso y ascenso de resonancias neoplatónicas. Así, en IV 18 -13, la imagen del sol y sus rayos se emplea como descripción del efecto que Dios tiene como Bondad Fontal, que envía sus rayos por el mero hecho de ser: ${ }^{12}$

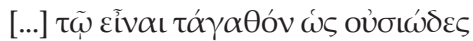

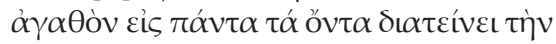

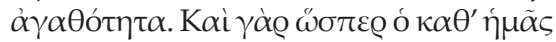

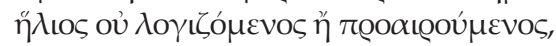

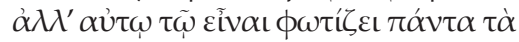

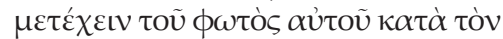

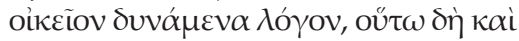

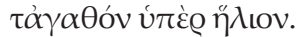

[...] por el mismo hecho de ser, el Bien en tanto que Bien Fontal extiende su bondad a todos los seres. Como nuestro sol, sin voluntad ni libertad, sino por el mismo hecho de ser, alumbra a todas las cosas que participan, según su medida, de su luz, de la misma manera el Bien que está más allá del Sol.

En coherencia con esta idea, el autor va describiendo la gradación del ser, desde las jerarquías celestes hasta los objetos inanimados, como causados por esta bondad difusiva que emana de Dios, Bien Supremo. En IV 3 y 4 aparece definido este Bien Supremo como aquel que está por encima de los seres y del ser mismo, y como aquel que sin tener forma da forma a las

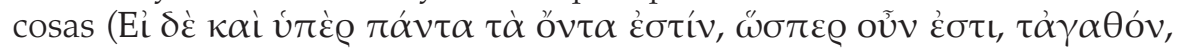

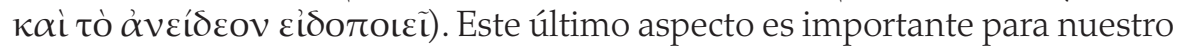
estudio, pues la belleza aparece siempre asociada en el pensamiento platónico-cristiano con la forma. Si Dios es fuente de las formas, es fuente, como veremos, de la belleza.

Abordando ya IV 6-7, en ellos el Pseudo Dionisio se pregunta con qué razón Dios es llamado "Belleza" en los siguientes términos:

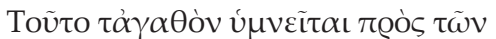

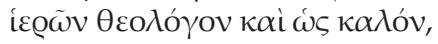

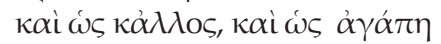

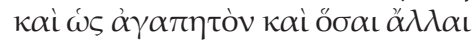

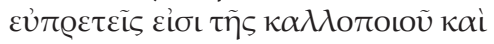

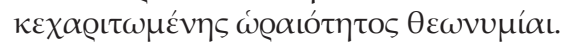

Este Bien es celebrado por los santos teólogos también como Bello y Belleza, y como Amor y Amado, y todos los nombres divinos que convienen a la Belleza en su plenitud, embellecedora y llena de gracia.

Como se puede comprobar, el texto no tiene desperdicio. En primer lugar, encontramos la asociación entre la idea de belleza y la de amor. Ambos son nombres de Dios que están íntimamente relacionados como ya vimos en Platón. Pero quizás sea más interesante los dos adjetivos con los que

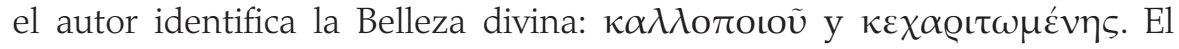

12 Mientras no se indique lo contrario, las traducciones son nuestras, basadas en la edición bilingüe referida en la nota 7 . 
primero, que hemos traducido imperfectamente por"embellecedora" (como haceYsabel de Andia, que lo vierte como"embellissante"), es un compuesto que literalmente significa "hacedora de belleza". Dios es la causa de toda belleza sensible porque es el que la hace, el que la crea. Desde esa óptica, todas las cosas son obras bellas de Dios, como dirá luego la Summa Fratis

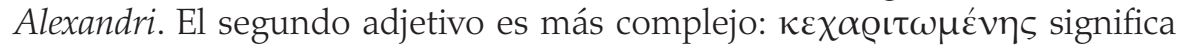
literalmente "la que ha sido llenada de gracia". Es el mismo adjetivo usado que el ángel dirige a María en Lc 1,28: "Alégrate, llena de gracia". Tiene así profundas resonancias bíblicas que enlazan con la idea de un vínculo profundo entre el plan de Dios y la belleza.

Ahora bien, ¿qué relación tiene la belleza de los seres creados con esta Suma Belleza? En IV 7, lo explicará el autor:

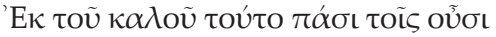

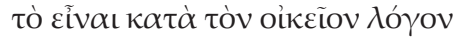

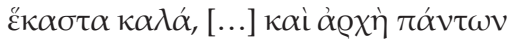

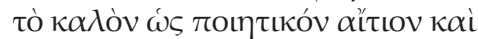

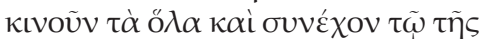

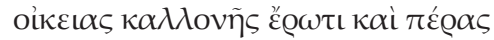

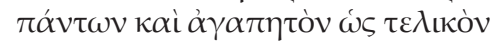

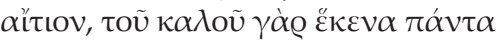

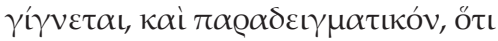

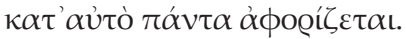

De esa Belleza resulta para todos los seres el hecho de ser bellos cada uno según su propia razón. [...]. Por ello, la Belleza es el principio de todas las cosas como causa eficiente, que los mueve a todos y los mantiene por amor de su propia belleza. Está al fin de todas las cosas como causa final y como Bienamado, pues todas las cosas son creadas en vista de la Belleza y en tanto que paradigma.

El texto es bastante claro pero conviene destacar sus ideas principales. En primer lugar, la Belleza divina es causa de la belleza sensible, tanto en su origen (causa eficiente) como en su teleología (causa final). Asimismo, las cosas bellas subsisten por el amor que la Belleza Divina tiene de sí misma (concepto de resonancias aristotélicas), de la cual las cosas bellas son ejemplos, paradigmas.

En este texto se culmina la ontologización de la belleza. Todo lo que en el mundo creado pueda parecer bello a los hombres proviene de la Suma Belleza, que se identifica con el Dios cristiano. De tal forma, la percepción sensible de algo bello a los ojos de los hombres es un reflejo de la belleza divina y un camino de ascenso hacia la realidad trascendente, de tal forma que no tiene un valor en sí, sino como medio de ascenso a realidades más altas. Así, la belleza de la naturaleza y de las obras de los hombres se ordena hacia Dios, causa eficiente, final y ejemplar de todo lo bello. Sin embargo, el Pseudo-Dionisio no llega a afirmar que todas las cosas sean bellas por el hecho de haber sido creadas.

Ahora bien, resulta interesante que, para concluir, estudiemos la ex-

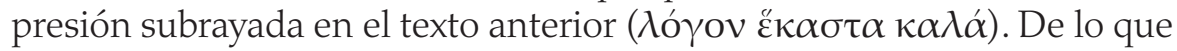
hemos expuesto parecería que la forma sensible es de poca importancia a la hora de juzgar la belleza, pues es la participación del ser divino lo que 
la determina. Sin embargo, el mismo Dionisio reconoce que las cosas son

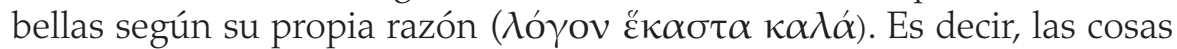
bellas tienen un $\lambda o ́ \gamma o \varsigma$, que en este caso podría ser definido como una estructuración, una forma aprehensible que hace bellas las cosas a los

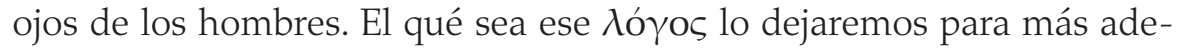
lante, pues Tomás de Aquino nos dará la clave.

Pero resulta importante destacar que esa mención abre una brecha entre dos conceptos de belleza: la belleza metafísica, propia de la participación de todos los seres, y la belleza estética, que resulta del $\lambda$ ó $\gamma$ os que tiene la cosa y de la que hablaremos en la segunda parte. Veremos como esa distinción se irá profundizando en siglos posteriores. Es esta segunda noción de belleza, o esta segunda orientación del concepto, el que se va a ir vinculando progresivamente con el arte.

\subsection{La belleza ontológica y el arte. Escoto Eriúgena, Suger de Saint-Denis y la estética del gótico ${ }^{13}$}

La ontologización de la belleza que hemos descrito en el Pseudo Dionisio hace su aparición en Occidente gracias a las traducciones que de sus obras hace Escoto Eriúgena, y a su obra propia De divisione naturae (Peri physeon). Esta recoge la metafísica del Pseudo Dionisio en muchos aspectos, entre ellos la participación de todos los seres en la belleza divina. Sin embargo, no nos vamos a extender demasiado en el pensamiento de Eriúgena por ser más metafísico que estético. Será Suger de Saint-Denis el encargado de trasladar las ideas filosóficas del platonismo cristiano a una reflexión sobre el arte, su belleza y su función. Suger vincula expresamente el arte bello, el arte como obra humana con su logos interno, con la belleza (estética), que refleja la belleza (metafísica) divina.

¿Quién era Suger de Saint-Denis (1081-1151)? Monje benedictino, abad de Saint-Denis, incluso regente de Francia durante la Segunda Cruzada (1144-1148), Suger se nos presenta como una figura clave de la historia de Francia y de la consolidación de su monarquía. Contemporáneo, pero al mismo tiempo muy distinto a otro gran personaje del tiempo, Bernardo de Claraval, Suger fue ministro, diplomático y consejero de diversos reyes, pero también fue un abad reformador que introdujo en su monasterio una observancia más pura de la Regla de

13 En este apartado resumimos los resultados de Erwin PANOFSKY, El abad Suger. Sobre la Abadía de Saint-Denis y sus tesoros artísticos, Madrid, Alianza, 2004, 26-53 y de Werner BeIERWaltes, Eriúgena: aspectos esenciales de su pensamiento, Pamplona Eunsa, 2009, 111-153. 
San Benito en 1127, por lo que fue felicitado por el mismo Bernardo de Claraval.

Sin embargo, la figura de Suger nos interesa aquí como mecenas y hombre que reflexiona sobre el papel del arte y de su belleza. La reflexión de Suger se encuadra en un contexto marcado por dos circunstancias históricas fundamentales: la reforma que Suger emprende de la iglesia de su monasterio y la polémica entre benedictinos y cistercienses sobre el arte sacro. Como de la primera circunstancia vamos a tratar más adelante, conviene que expongamos brevemente la polémica entre monjes negros y monjes blancos. ${ }^{14}$

Con el nacimiento del movimiento reformador del Císter, las polémicas con el monacato tradicional (benedictinos negros) no se iba a hacer esperar. Será la afilada pluma de Bernardo de Claraval, entre otros, la que inicie la polémica sobre los distintos modos de vida de ambos movimientos monásticos. En su Apologia ad Willelmum abbatem el de Claraval acusará a los monjes negros de un exceso de ornato en sus iglesias, de amar el oro y las piedras preciosas más que a Dios mismo. Sin embargo, San Bernardo no innova en las aceradas páginas de la Apologia, pues no hace otra cosa que recoger lo que en aquellos mismos años, en 1138, legislaban los cistercienses para sus iglesias:

Prohibimos que haya esculturas o pinturas en nuestras iglesias o en algunas habitaciones del convento, pues al contemplarlas se olvida muchas veces la conveniencia de la buena meditación y la disciplina de la autoridad religiosa. Sin embargo, tenemos cruces pintadas, que son de madera. ${ }^{15}$

Como se puede comprobar, los escritos de Suger sobre el arte sacro se encuadran en una polémica sobre la utilidad y conveniencia del mismo en las iglesias. Numerosos son los textos que se escribieron desde el bando cisterciense y algo menos numerosos los que escribieron los monjes negros para defender su concepción del arte. De entre estos escritos destacamos el Liber de administratione sua gestis de Suger, donde da noticia de sus actividades como restaurador y reformador de la basílica de Saint-Denis. Se trata de un texto extraordinario, donde no solo encontramos uno de los pocos testimonios de un mecenas justificando su actividad artística, sino sobre todo una consideración sobre el valor del arte en una iglesia frente a los impugnadores del mismo, reflexión que le lleva a profundizar sobre el papel que tiene la belleza artística.

14 Cf. García Ma Colombás, La Tradición Benedictina. Ensayo Histórico. IV-2: el siglo XII, Zamora, Monte Casino, 1993, 507-588.

15 Instituta Generalis Capituli Cisterciensis, art. 20, citado en Wladyslaw Tatarkiewicz, Historia de la estética, II: la estética medieval, Barcelona, Akal, 1988, 183. 
En este texto, Suger cristaliza las reflexiones metafísicas que hemos expuesto en el apartado anterior en una concepción del arte como camino hacia Dios. Así, la basílica de Saint Denis y su belleza sensible se convierte en un medio para trascender lo visible hacia lo inteligible, hacia la suprema belleza, que es Dios. En palabras de Eriúgena, nihil visibilium rerum corporaliumque est, quod non incorporale quid et inteligibile significet. ${ }^{16}$ De hecho, el mismo Suger, al describir las puertas de la basílica, recoge unos versos compuestos por él que condensan su concepción del arte: ${ }^{17}$

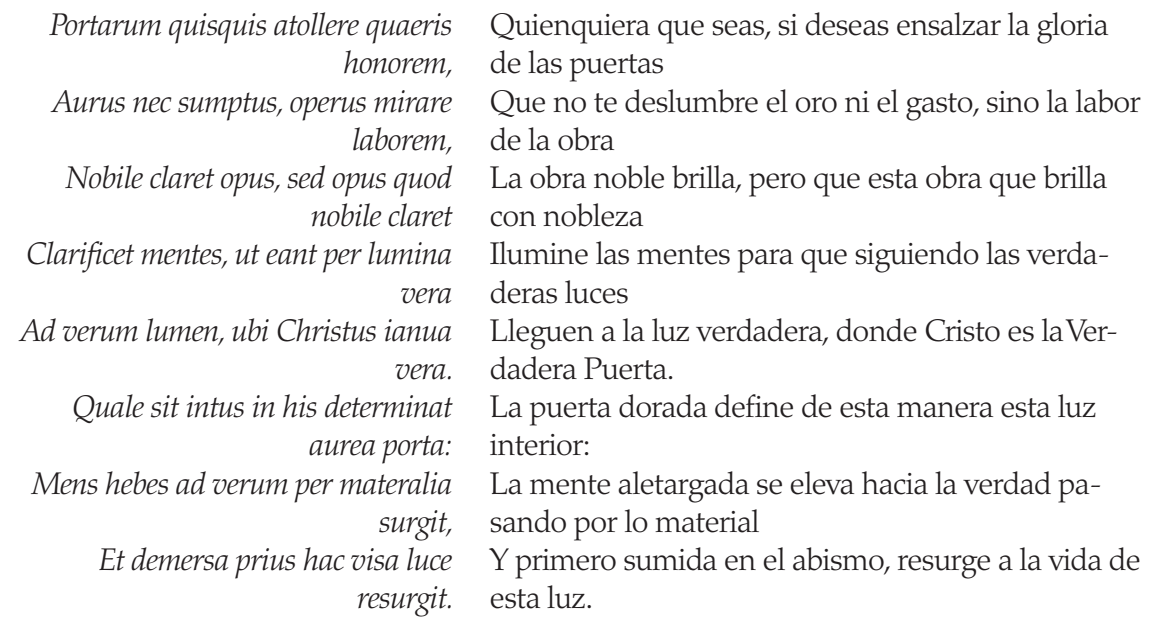

Con este texto llegamos al corazón de la primera estética medieval, lo que muchos estudiosos llaman la función anagógica del arte: el arte como medio para llegar a Dios. Son muchos los textos de Suger que podríamos citar en defensa de esta concepción del arte pero vamos a destacar uno. En él, Suger proporciona una mirada algo íntima al efecto que a él le produce la belleza de la casa de Dios:

Por esta razón, al arrancarme, por amor a la belleza, de mis preocupaciones externas la casa de Dios, a veces multicolor, y la hermosura de las piedras preciosas, una honesta meditación me obligaría a perseguir también las diversas virtudes santas, transportándome de lo material a lo inmaterial; me parece verme casi atrapado bajo una extraña red del mundo terrenal, que ni está totalmente sobre la faz de la tierra ni en la pureza del cielo, y poder pasar de esta esfera inferior a la superior, a través del camino que me ofrece la voluntad de Dios. ${ }^{18}$

16 Iohannis scotti seu Eriugenae, Periphyseon, V, 3, 865, en Beierwaltes, Eriúgena, 149-150.

17 Suger de SaInt-Denis, Liber de administratione sua gestis, XXVII en PANOFSKY, El Abad Suger, 64-65.

18 Suger de SAInt-Denis, Liber de administratione sua gestis, XXXII en PANOFsky, El Abad Suger, 81. 
Como se puede comprobar, con Suger estamos en un punto de inflexión del pensamiento tanto metafísico como estético en Occidente. Sus reflexiones ponen de manifiesto la fecundidad del pensamiento platónico-cristiano de los siglos anteriores en relación con la belleza ontológica. Así, más allá de las puras especulaciones metafísicas, la concepción platónico-cristiana de la belleza va a derivar en una concepción concreta del arte. Sin embargo, las limitaciones de esta visión son patentes: la belleza se ve como camino de ascensión pero no existe una reflexión precisa sobre qué sea esa belleza. Suger vincula su estética ontológica al arte, pero no trata de la belleza sensible más que como un medio para la contemplación de las realidades celestes.

\subsection{El culmen de la ontologización de la belleza: la escuela franciscana}

En el desarrollo de la metafísica de la belleza resultó crucial el impulso que la escuela franciscana del siglo XIII dio a la noción de belleza y que luego Santo Tomás recogerá y al mismo tiempo reconducirá. Así, la segunda parte de la Summa fratris Alexandri, atribuida a Alejandro de Hales pero compuesta por diversos franciscanos, ${ }^{19}$ se dedica a desarrollar la primera metafísica de la belleza entendida como perteneciente a todo ente por el mero hecho de ser. Podríamos decir que es el primer tratado sobre la belleza en sí, que recoge el legado de pensadores anteriores y, desde ellos, desarrolla una línea propia de pensamiento.

Siguiendo al Pseudo-Dionisio, para la Summa fratris Alexandri la Belleza tiene un vínculo estrecho con la Bondad y la Verdad del ser, pero al mismo tiempo debe ser distinguida de ellos. La Belleza y el Bien, nos dice, son ídem in substantia, differunt in ratione, idénticos en substancia pero con una diferencia de razón (y ya encontramos aquí ecos del De Veritate de santo Tomás), diferencia que se concreta en que el Bien hace referencia a la causalidad final mientras que la belleza lo hace a la causa formal.

En efecto, a la hora de hablar de la belleza el concepto de forma (formosus no deja de significar bello en latín) es clave. Para Considerans la belleza y la verdad tienen que ver con la forma, pero de maneras distintas. Si la verdad se entiende como una disposición de la forma en el interior, la belleza es justamente la disposición de la forma en relación con el exterior. ${ }^{20}$ Aquí aparece un rasgo fundamental de la belleza en su consideración como propia de todo ente: su "manifestabilidad", si se

19 La tercera parte es atribuida a un franciscano anónimo llamado Frater Considerans.

20 Veritas est dipositio ex parte formae relata ad interitus, pulchritudo vero est dispositio ex parte formae relata ad exterius. Cfr. Summa Fratris Alexandri (ed. Quaracchi), II, 75. 
nos permite el neologismo, es decir, su aptitud para manifestarse externamente, su vínculo con la percepción, lo que va a tener importantes consecuencias. Como afirma M. Palma, citando a H.U.Von Balthasar: “La belleza se presenta al sujeto, antes que nada, como «manifestación»: en su aparición, la belleza es transparencia del fondo misterioso que es el ser, de hecho, la tensión entre lo material y la interioridad funda en una paradoja el misterio de la belleza".$^{21}$

Así, la belleza se presenta como relativa a la disposición externa, a la species. Dado que todo ente se manifiesta bajo una forma determinada para poder ser comprendido (revelando el conjunto armonioso del universo), la belleza entendida como forma es característica de todos los entes, es un trascendental del ser. ${ }^{22}$ Como dirá después San Buenaventura: omne quod est ens habet aliquam formam, omne autem, quod habet aliquam formam, habet pulchritudinem. ${ }^{23}$ Con afirmaciones como esta se llega al mayor desarrollo filosófico de la noción de belleza metafísica que hemos estado describiendo.

La conclusión de San Buenaventura es obvia pero no por ello deja de ser inquietante: si todo tiene forma, y la forma proviene de Dios, todo ser es bello. Entonces, ¿qué sería lo específico de la belleza? Es interesante recordar que el mismo Considerans llega a afirmar que res monstruosae sunt pulchrae. ${ }^{24}$ Ese es quizás el problema que lleva aparejado el concepto de belleza metafísica: la pérdida de su propia especificidad al convertirse en lo "manifestable" del Bien. Por mucho que se insista en la forma, no hay tanto referencias a la aprehensión sensible de esta forma como consideraciones abstractas sobre la misma. Por ello nos encontramos con una concepción metafísica de la belleza, donde la belleza es una propiedad de los seres, no algo que se perciba. Si todas las cosas son obra de Dios, son buenas y por tanto bellas. Recordemos así que empezamos esta primera parte con la identificación en Dios entre Bien y Belleza.

Ahora bien, no convendría tampoco olvidar que hay un aspecto de la belleza metafísica que, aunque en estos textos no aparece expresamente, esta detrás de ellos: el amor. Ya hemos visto como en algunos autores belleza y amor son dos conceptos íntimamente relacionados. Así, sostener que la Belleza y el Bien son trascendentales del ser no implicaría una redundancia ni una cuestión de matiz. La belleza del ser, el splendor de todas las cosas por el mero hecho de ser obra divina, sería un estímulo

21 Manuel Palma Ramírez, "Por la senda luminosa de un camino abandonado: via pulchritudinis y metafísica", Isidorianum 43 (2013) 16.

22 Cf. Paul Gilbert, Metafísica, la paciencia de ser, Salamanca, Sígueme, 2008, 378.

23 II Sent. D. 34 a. 2 q. 3.

24 Summa Fratris Alexandri (ed. Quaracchi), II, 79. 
para el amor a lo creado y de ahí a Dios. El patrón ascensional de raigambre platónica sigue presente.

La belleza metafísica sería de esta manera un camino privilegiado de conocimiento, una forma alternativa al conocimiento racional para descifrar el ser de las cosas. Estas intuiciones son las que santo Tomás, aunque partiendo de presupuestos muy distintos, va a conservar en sus reflexiones sobre la belleza metafísica y sobre la belleza que empezaremos a llamar"formal" en la segunda parte de este estudio.

\section{SEGUNDA PARTE: LA FORMA Y LA BELLEZA “FORMAL"}

En la primera parte del estudio hemos visto como se ha dado una progresiva ontologización de la belleza de tal forma que aquello que podríamos llamar" "belleza formal", fruto de la percepción de los sentidos sobre las cosas, naturales o artísticas, ha quedado de lado o como mucho ha quedado subordinada a ser un medio de acceso a Dios. La belleza ontológica se ha impuesto a la belleza formal. Pues bien, en esta segunda parte vamos a seguir la pista a esta belleza formal en autores como San Agustín para poder entender como Santo Tomás opera una síntesis de ambas clases de belleza, destacando la importancia de la belleza formal y ayudando a la progresiva conquista de la autonomía del arte respecto a presupuestos metafísicos.

\subsection{La belleza como forma y el arte como imitación: la herencia de la filosofía antigua en San Agustín y Boecio}

Ya pudimos comprobar como el Pseudo Dionisio, en medio de las nieblas metafísicas, era capaz de afirmar que las cosas bellas lo eran porque tenían su propio logos. Con esta afirmación se estaba haciendo eco de la concepción de belleza que hemos denominado "formal", es decir, la que resulta de la armonía y proporción de los elementos, no de su participación en una belleza del ser o de Dios. Esta concepción de la belleza hunde sus raíces en la filosofía griega. No deja de ser llamativo que sea Platón, el padre de la ontologización de la belleza, el que también haya reflexionado más sobre este aspecto de la belleza, singularmente en el diálogo Hipias Maior.

Uno de los diálogos de juventud, el Hipias Maior, es el primero en tratar la cuestión de la belleza de forma extensa, aunque el diálogo no alcanza una conclusión clara (es uno de los diálogos calificados de aporético). Pero en lo que a nosotros nos interesa, el diálogo que mantienen Hipias y Sócrates es un ejemplo de las diferentes definiciones de la 
belleza que se basan en una idea de armonía de las formas: lo bello es lo útil ${ }^{25}$ y lo que da placer, ${ }^{26}$ aspectos que resultan del equilibro y de la armonía de las formas. Asimismo, ya vimos como en Banquete la belleza sensible se entiende también en esta línea de armonía. Así, la primera etapa ascensional descrita en el Banquete pasa por la belleza de los cuerpos, es decir, por la aprehensión sensible. Aunque para Platón sea más importante la Belleza en sí, no deja de tener presente la belleza formal.

Junto con esta idea de belleza formal, el otro pilar que vamos a ver reflejado en el pensamiento de Santo Tomás es la idea de arte como imitación. Desgraciadamente no podemos entrar en la teoría del arte de Santo Tomás porque excedería los límites de este estudio, centrado en el concepto de belleza. Baste decir que Santo Tomás acoge la noción aristotélica de imitación (mímesis) al afirmar en su comentario a la Física de Aristóteles que ars imitatur natura. ${ }^{27}$

Ambas ideas (belleza como armonía de la forma y arte como imitación) van a ser claves en la reflexión tomasiana que vamos a ver a continuación, pero es necesario que nos detengamos brevemente en un eslabón intermedio de la transmisión del pensamiento estético antiguo: se trata de san Agustín. Agustín, que es junto con Aristóteles el autor que más ha influido en los escritos de Santo Tomás, ${ }^{28}$ no tiene un tratado específico sobre cuestiones estéticas, sino que sus consideraciones sobre la belleza se hallan dispersas por sus abundantes escritos.

A modo de ejemplo hemos seleccionado su escrito De Musica, que a nuestro juicio aúna la herencia platónica y aristotélica a la hora de hablar de una forma específica de arte: la música. En este escrito, Agustín trata en forma de diálogo diversas cuestiones sobre el ser de la música. Dividido en 6 libros, los 5 primeros tratan cuestiones formales, mientras que el sexto, el más extenso, retoma la noción ontológica de belleza y la considera como

25 "Llamamos bellas a todas estas cosas por la misma razón, porque consideramos en cada una de ellas para qué han nacido, para qué han sido hechas, para qué están determinadas, y afirmamos que lo útil es bello teniendo en cuenta en qué es útil": Platón, Hipias Maior 295c en Platón, Diálogos I, (Biblioteca Clásica Gredos 37), Madrid, Gredos, 1981, 426.

26 "Los seres humanos bellos, Hipias, los colores bellos y las pinturas y las esculturas que son bellas nos deleitan al verlos. Los sonidos bellos y toda la música y los discursos y las leyendas nos hacen el mismo efecto, de modo que si respondemos a nuestro atrevido hombre: «Lo bello, amigo, es lo que produce placer por medio del oído o de la vista», ¿no le contendríamos en su atrevimiento?": Platón, Hipias Maior 298a en Platón, Diálogos I, 430.

27 In Phys. II, 4, citado en Tatarkiewicz, Historia de la estética, II, 274.

28 Alexander Fidora, "Augustine to Aquinas", in B. Davies - E. Stump (eds.), The Oxford Handbook of Aquinas, Oxford, OUP, 2012, 46. 
reflejo de la luz divina. Nos centraremos en esos primeros libros, donde la música aparece definida como la ciencia de modular bien. ${ }^{29}$

En el análisis de esta definición Agustín pondrá el acento en la última palabra: bien. Modular bien significa para San Agustín hacerlo de acuerdo con unas reglas y una lógica interna. Así, más adelante afirmará:

La Música es el arte del movimiento ordenado, Y se puede decir que tiene movimiento ordenado todo aquello que se mueve armoniosamente, guardadas las proporciones de tiempos e intervalos (ya, en efecto, deleita, y por esta razón se puede denominar ya modulación sin inconveniente alguno). ${ }^{30}$

Vemos como lo que Platón había dicho en Hipias Maior no está muy lejos de lo que afirma Agustín. El orden, la armonía y la proporción son aspectos básicos del arte, los que lo hacen atractivo, deleitoso, bello. La música es bella porque tiene estas características. De hecho, el mismo Agustín se servirá de ese criterio para diferenciar en De Musica I, IV, la música de otros fenómenos sonoros como el canto de los pájaros.

Por otro lado, al mismo tiempo que entiende la forma de la música como fuente de su belleza, De musica es consistente con la noción aristotélica de arte como imitación. Así, afirmará en I, 4, 6 que"la imitación tiene tanta importancia en las artes que, si se la suprime, morirían casi todas ellas". Asimismo, vincula la imitación con la razón cuando dice:

Dijiste que es arte, y afirmaste que esto tiene tanta importancia que, si se suprimiese la imitación, te parecerían estar en peligro casi todas las artes. De lo cual puede ya colegirse que todo el que consigue algo por medio de la imitación está haciendo uso del arte; aunque quizá no todo el que hace uso del arte lo adquiere por imitación. Ahora bien: si toda imitación es arte y todo arte es razón, toda imitación es razón. ${ }^{31}$

Puede comprobarse como San Agustín se convierte en el autor que vincula en sus reflexiones belleza formal y arte como imitación —Platón y Aristóteles-, en una concepción que, si bien no dejará de estar presente en el pensamiento medieval, se verá eclipsada por las consideraciones metafísicas sobre la belleza. Sin embargo, la obra de San Agustín va a ser también el presupuesto necesario para que autores posteriores, como Hugo de San Víctor o Santo Tomás de Aquino, vuelvan a poner el acento en el carácter formal de la belleza, abriendo así camino a la vinculación entre arte y belleza.

29 De Musica I, II, 2 en San Agustín, Obras completas vol. XXXIX, Escritos varios, Madrid, BAC, 1988, 73.

30 Ibidem, I, III, 4 (BAC p. 78).

31 Ibidem, I, IV, 6 (BAC p. 83). 
De la misma forma, otros autores como Boecio van a ejercer una influencia palpable en el pensamiento medieval en relación con las reflexiones sobre la belleza, también en este caso en su vertiente más formal y menos ontológica. En su obra Sobre el Fundamento de la Música Boecio se convierte en transmisor de las nociones de raigambre pitagórica sobre la música, centradas en la base matemática de los intervalos musicales. Así, la música aparece aquí también como en Agustín como un arte sometido a reglas formales que crea belleza y suscita en el hombre reacciones diversas. Escuchemos a Boecio:

Puede reconocerse también lo que no en vano quedó dicho por Platón: que el alma del mundo está conjuntada a base de un convenio musical. Cuando, en efecto, mediante lo que hay en nosotros conjuntado y convenientemente ensamblado captamos aquello que en los sonidos está ajustado y convenientemente conjuntado, y nos deleitamos con ello, nos damos cuenta de que nosotros mismos estamos configurados a imagen y semejanza. ${ }^{32}$

Como se puede comprobar la palabra clave aquí es ajuste: no se trata de emitir sonidos simplemente, sino que para que el hombre sintonice con la música tiene que darse un ajuste entre este y la música y eso se produce cuando el sonido se somete a la forma. El hombre sintoniza cuando capta la belleza del sonido y se deja llevar por las sensaciones que este le produce. En el libro I de la obra, Boecio se centra en los aspectos que constituyen bella la música: la forma, la proporción y el número. Así se mantiene en la línea agustiniana que ve en el número (forma) la base de la belleza. ${ }^{33}$

Tras las reflexiones de san Agustín y las de Boecio hay un planteamiento que, si bien incide en el aspecto formal de la belleza y de las cosas bellas como proporcionadas, no debe considerarse al margen de la metafísica que subyace. En efecto, aunque los autores que estamos trayendo a colación en esta segunda parte ponen el acento en el aspecto más formal y por tanto más aprehensible por los sentidos de las cosas llamadas bellas o de las obras de arte, en ningún caso estos autores lo hacen en desconexión de una opción metafísica previa. La opción va a ser de perspectiva, no de planteamiento de fondo.

Así, el Pseudo-Dionisio y quienes después continúan su línea de pensamiento parten de consideraciones metafísicas sobre el ser y a partir de ellas reflexionan sobre la belleza. La línea de autores como Agustín, Boecio y los que veremos a continuación llevan a cabo reflexiones sobre la belleza o sobre las artes consideradas en sí mismas, pero en consonancia

\footnotetext{
32 Boecio, Sobre el fundamento de la música, Madrid, Gredos, 2009, 62.

33 Cf. TATARKIeWicz, Historia de la estética, II, 84.
} 
con opciones metafísicas previas. En el caso de Agustín y Boecio resulta evidente cuando comprobamos la gran influencia que sobre su pensamiento sobre la música tuvo la reflexión filosófica pitagórica y platónica sobre la armonía del cosmos y la armonía del hombre unidas bajo la metafísica de los números y las proporciones. ${ }^{34}$

\subsection{Una aproximación intermedia: Hugo de San Víctor}

A medio camino entre la belleza ontológica y formal tenemos que situar un autor menos conocido pero que ha llevado a cabo una interesante síntesis en sus consideraciones sobre la belleza. Asimismo, si por algo destaca Hugo de San Víctor es por aplicar sus especulaciones sobre la metafísica de la belleza a las artes y a la actividad humana en general, acercando arte y belleza. Por ello, aunque sus concepciones derivan de las nociones del Pseudo-Dionisio en algunos aspectos, lo situamos aquí, en el camino hacia un tratamiento más detallado del aspecto formal de la belleza, que culminará en la Edad Media con Santo Tomás en el siglo XIII.

Hugo de San Víctor, (1096-1141), canónigo regular de la abadía de San Víctor en París, constituye una feliz excepción en la historia del pensamiento, donde a menudo capacidad analítica e intuición han ido por separado. La obra de los miembros de la escuela de San Víctor, los llamados "victorinos" se ha caracterizado por su capacidad clasificatoria y analítica pero al mismo tiempo por su impulso místico. ${ }^{35}$ Hugo pasará también a la historia por haber sido el maestro del que luego será conocido como el Magister por excelencia: Pedro Lombardo.

Entre las obras de Hugo de San Víctor encontramos una gran variedad de temas. La Iglesia le recuerda por su doctrina sobre los sacramentos en el De Sacramentis o el De Tribus Diebus, la filosofía le ve como un transmisor de la doctrina del Pseudo-Dionisio en su comentario al De Caelesti Hierarchia. En todas estas obras expone Hugo una visión del mundo de corte dionisiano-platónico. Así, como destacan autores como

34 Así lo afirman J. Luque Moreno y A. López Eisman en su introducción al De Musica: "la doctrina pitagórico-platónica sobre la implicación que tanto en la estructura psicosomática del hombre (el microcosmos) como en el orden sistemático del universo (el macrocosmos) tiene dicha estructura numérica, que la música expresa y hace sensible, se mantiene en pleno vigor a todo lo largo y lo ancho del mundo romano". Cf. San Agustín, Sobre la música. Seis libros, Introducción, traducción y notas de J. Luque Moreno y A. López Eisman, Madrid, Gredos, 2007, 16.

35 Cf. Paul Rorem, Hugh of St. Victor, Oxford, OUP, 2009, 11-14. Esta obra constituye un excelente acercamiento a la obra de Hugo de San Víctor teniendo en cuenta las investigaciones más recientes sobre la cronología de su obra y su papel como educador. 
Dominique Poirel, ${ }^{36}$ gran experto en Hugo, y Paul Rorem, ${ }^{37}$ el pensamiento de Hugo sobre el mundo asume la cosmovisión bíblica y la metafísica platónico-cristiana.

Así, partiendo del texto de Rom 1,20 que ya hemos citado, Hugo considera el mundo como un escenario donde hallar a Dios. La belleza de las criaturas se manifiesta como un camino de acceso a la belleza de Dios. Ahora bien, la originalidad de Hugo de San Víctor reside en que esta belleza metafísica aparece ligada a la belleza formal. No se va a tratar ya de un esquema de descenso (de la belleza de Dios se deduce que las criaturas son bellas porque le reflejan) como el de Dionisio, sino que la forma bella de las cosas es lo que va a permitir ascender hacia Dios.

En ese sentido es importante un texto de tratado De Tribus Diebus, sobre la creación, donde Hugo manifiesta en qué consiste la belleza de las cosas. ${ }^{38}$

Decor creaturarum est in situ et modu et specie et qualitate. Situs est in compositione et ordine. Ordo est in loco et tempore et proprietate.
La belleza de las criaturas se halla en la situación, el movimiento, el aspecto y la calidad. La situación está en la composición y el orden. El orden en el lugar, el tiempo y la cualidad.

Interesa esta definición de la belleza por el contraste que supone con las concepciones de belleza que hemos estudiado en la primera parte. Como veremos también con Santo Tomás, Hugo de San Víctor pone el acento en la disposición de la cosa, del objeto estético a la hora de determinar su belleza. Esta aparece determinada por una serie de factores que a continuación Hugo define. Entre ellos, nos interesan sobre todo los dos últimos, aspecto y calidad. Así los define Hugo:

36 Cf. Dominique PoIrel, Des Symboles et des anges: Hugues de Saint Victoir et le réveil dionysien du XII siècle, Tournhout, Brepols, 2013. Cf. en especial el capítulo II: "La figure du Pseudo-Denys chez Hugues de Saint Victor", 149-194, donde el autor da cuenta de la influencia del Pseudo-Dionisio en las obras del Hugo de San Víctor.

37 Cf. ROREM, Hugh of St. Victor, 62-63.

38 Hugo de San Víctor, De tribus diebus, (ed. D. Poirel) (Corpus Christianorum 177), Turnhout, Brepols, 2002, 4. Este opúsculo fue tenido mucho tiempo por el séptimo libro del Didascalicon y como tal aparece en la edición del mismo de la Patrologia Latina de Migne (PL 176, 311-386). Sin embargo, en su edición para el Corpus Christianorum, Poirel muestra que es una obra diferente por su contenido y sus temas, de índole teológico-especulativo. 
Species est forma visibilis, quae oculo discernitur, sicut colores et figurae corporum. Qualitas est proprietas interior, quae ceteris sensibus percipitur, ut melos

in sono audito aurium, dulcor in sapore gustu faucium, fragrantia in odore olfactu narium, lenitas in corpore tactu

manuum.
El aspecto es la forma visible que discierne el ojo, como los colores y las figuras de los cuerpos. La calidad es una propiedad interna que perciben algunos sentidos, como la melodía del sonido escuchada por el oído, el dulzor del sabor por el gusto de la boca, el olor de la fragancia por el olfato de la nariz o la suavidad del cuerpo palpada por las manos.

La belleza aparece así profundamente vinculada con el aspecto sensible de las cosas, con los sentidos, tanto la vista como el resto. Hugo de San Víctor separa la vista de los demás sentidos como el principal perceptor de la forma (species, término cargado de significados y referencias platónicas) y por tanto de la belleza. Así, Hugo de san Víctor puede ser considerado como uno de los adalides de la belleza considerada como forma, retomando intuiciones de autores que ya hemos estudiado, pero sistematizándolas.

Al mismo tiempo, no se puede olvidar que su punto de partida es una metafísica de raigambre platónica. Esto se muestra claramente si tenemos en cuenta que el pasaje de De Tribus Diebus que acabamos de citar viene precedido por consideraciones sobre la creación del mundo visible por parte de Dios. ${ }^{39}$ Este mundo es para el Victorino fruto del poder, de la sabiduría y la misericordia de Dios. Estas tres potencias divinas dan lugar al mundo, y este al mismo tiempo las manifiesta. Entre ellas, Hugo considera que la belleza de las cosas manifiesta la sabiduría de Dios. Por ello, podemos comprobar cómo Hugo altera el esquema platónico de Dionisio para acercarlo a San Pablo (cf. Rom 1,20). La belleza de las cosas (entendida como acabamos de ver como una cierta proporción) manifiesta la belleza de Dios, frente el esquema descendente dionisiano. Esto puede verse muy bien un fragmento del comentario al De Caelesti Hierarchia que recoge W. Tatarkiewicz. ${ }^{40}$

39 Cf. RoRem, Hugh of St. Victor, 63.

40 TATARKIEWICZ, Historia de la estética, II, 208. 
Idcirco alia est pulchritudo visibilis et alia invisibilis naturae, quoniam illa simplex et uniformis est, ista autem multiplex et varia proportione conducta. Est tamen aliqua similitudo visibilis pulchritudinis ad invisibilem pulehritudinem, secundum aemulationem, quam invisibilis artifex ad utram que eonstituit, in qua quasi speculamina quaedam diversarum proportionum unam imaginem effingunt. Secundum hoc ergo a pulchritudine visibili ad invisibilem pulchritudinem mens humana convenienter excitata ascendit... Est enim hic species et forma, quae delectat visum; est suav

tas odoris, quae reficit olfatum; est dulcedo

saporis, quae infundit gustum; est lenitas corporum, quae fovet et blande excipit tactum.
Así pues, una cosa es la belleza invisible y otra la de naturaleza visible, pues la primera es sencilla y uniforme, y la segunda, compleja y variada. Sin embargo, existe cierta semejanza entre la belleza visible y la invisible, gracias a la imitación que el artífice de la invisible realizó entre ambas, en la cual, como en un espejo, de diversas proporciones se conforma una sola imagen. Por esta vía, pues, la mente humana, convenientemente impulsada, asciende de la belleza visible a la invisible... Aquí reside la hermosura y la forma que deleita la vista; la suavidad del olor, que reanima el olfato; la dulzura de sabor, que humedece el gusto; la delicadeza del cuerpo, que acaricia y acoge con dulzura el tacto.

Como se puede ver, el texto tiene muchos paralelos con el que hemos citado anteriormente, aunque ahora situado en una perspectiva más propia de la metafísica platónica. La belleza visible y la invisible aparecen en una especie de sincronía creada por Dios. El impulso ascensional que la belleza genera se vincula con la experiencia sensible de una forma que el PseudoDionisio no habría nunca planteado. Esta es una de las novedades de Hugo de san Víctor que lo convierten en un precedente de Santo Tomás, como veremos a continuación.

Junto con esta modificación del esquema de Dionisio, es interesante el giro que a este ascenso epistemológico da el autor frente a otras propuestas como la agustiniana. Así, para Hugo no se trata simplemente de ascender de las cosas bellas a la Belleza en sí, sino que, una vez se ha ascendido, corresponde descender de nuevo para dar testimonio de lo contemplado y ayudar a otros a alcanzar dichas cotas. El misticismo se mezcla aquí con la experiencia estética, que lleva además a desear que los demás compartan esta experiencia. ${ }^{41}$ Porque si por algo destacó Hugo es por su papel de educador. Por ello, no podemos olvidar que, además de reflexionar sobre la belleza en abstracto, Hugo llevó sus nociones sobre el aspecto sensible de la belleza al arte.

En efecto, su obra Didascalicon de studio legendi, o simplemente Didascalicon es una de las obras más importantes en relación con la pedagogía y la transmisión del saber en la Edad Media. ${ }^{42}$ La obra consiste

41 Cf. Rorem, Hugh of St. Victor, 64.

42 Contamos con una excelente edición biblingüe a esta obra llevada a cabo por Carmen Muñoz Gamero y $\mathrm{M}^{\mathrm{a}}$ Luisa Arribas Hernáez y coeditada por la UNED y la BAC: Cf. Hugo de SAn Víctor, Didascalicon de studio legendi: El afán por el estudio, edición 
en una especie de programa de estudios para los alumnos de la escuela de San Víctor, y sorprende por la amplitud de sus miras, pues trata desde la lógica hasta los oficios más humildes. Así, se trata de una gran clasificación de las ramas del saber destinada a los hombres de su tiempo como en otro tiempo lo fueron las Etimologías de san Isidoro de Sevilla. ${ }^{43}$

Dentro del Didascalicon es singular el tratamiento que el libro II da a las artes, donde la doctrina de la belleza formal que acabamos de ver se enlaza con las nociones sobre lo que es el arte y su ejecución. Así, Hugo comienza dando una definición de arte de hondas raíces en la tradición filosófica: Ars dicit potest scientia, quae artis praeceptis regulisque consistit ("Puede denominarse arte a la ciencia que se basa en las reglas y preceptos de un arte"), cita literal de las Etimologías de San Isidoro. ${ }^{44}$

No podemos dedicarle todo el tiempo que una obra tan singular como esta se merece. Baste decir que en su tratamiento de las artes (en un concepto de arte más amplio que el nuestro), Hugo pone el acento en sus aspectos materiales y formales como una manifestación de la actividad creadora del hombre. El hombre aparece así como un creador de belleza por medio del arte que, gracias a dicha belleza, ayuda a conocer a Dios. Esto lo podemos comprobar en el capítulo IX del libro I, donde se compara el trabajo de Dios, el trabajo de la naturaleza y el trabajo de los hombres. ${ }^{45}$ El trabajo del hombre como artesano es definido, como ya hicieron Aristóteles y Agustín, como opus artificis imitantur naturam ("el trabajo del artesano imita la naturaleza"). Así, el trabajo humano, entre el que se encuentra el arte, es concebido como imitación de la obra divina.

Por todo lo expuesto, Hugo de San Víctor aparece, al igual que lo fue San Agustín, como el eslabón de transmisión de un conjunto de ideas sobre la belleza que no se ajustan a la ortodoxia platónico-cristiana. El énfasis en lo sensible, la importancia del arte como imitación sometida a reglas y como actividad humana, o la concepción de la belleza como algo que determina la disposición formal de la cosa son aspectos que veremos en otros autores posteriores y que son algunas de las grandes aportaciones a la reflexión sobre la belleza realizada por Hugo de San Víctor. Asimismo, la vinculación entre metafísica y arte que hace Hugo no puede ser desdeñada, pues da testimonio de una modernidad sorprendente.

\footnotetext{
bilingüe preparada por Carmen Muñoz Gamero y Mª Luisa Arribas Hernáez, Madrid, UNED-BAC, 2011. En lo que sigue citaremos siempre esta traducción.

43 Cf. ROREm, Hugh of St. Victor, 26.

44 Hugo de San Víctor, Didascalicon, II, I, p. 54-55.

45 Hugo de San Víctor, Didascalicon, I, IX, p. 36-39.
} 


\subsection{Santo Tomás de Aquino y la belleza}

\subsubsection{Dificultades para el estudio de la belleza en Santo Tomás}

En todo lo relativo a Santo Tomás de Aquino y su pensamiento se verifica plenamente lo que enunciábamos al principio de este estudio: la abundancia de estudios e intérpretes del Aquinate a lo largo de siglos ha ido llenando de precomprensiones el pensamiento de Santo Tomás y ha utilizado sus textos para construir sistemas filosóficos no ajenos, pero sí lejanos a lo que el dominico del siglo XIII pretendía con sus escritos. En el caso de los breves pasajes que dedica a la belleza y a cuestiones estéticas, esto se ha verificado en diversos pensadores, entre los que destacan Jacques Maritain ${ }^{46}$ y Umberto Eco. ${ }^{47}$ El primero construye a partir de santo Tomás una reflexión admirable sobre la estética, que va sin embargo mucho más allá de lo que pensó el Aquinate, pues tiene presente problemas ontológicos y epistemológicos que no fueron tenidos en cuenta por el santo de Aquino dado el contexto de su producción filosófica. El segundo, en una obra clásica sobre la estética de santo Tomás, ha condicionado muchos de los estudios posteriores sobre estas cuestiones. Ante estas dificultades, nosotros nos vamos a remitir esencialmente a los textos de Santo Tomás y a intentar darles una interpretación acorde con la línea argumentativa que hemos ido sosteniendo en las páginas anteriores.

En su exposición sobre el pensamiento de Santo Tomás de Aquino, Mauricio Beuchot ${ }^{48}$ distingue en Santo Tomás una metafísica de lo bello y una filosofía del arte. La primera derivaría de consideraciones similares a las que hemos visto hicieron los franciscanos de su tiempo, pero tamizada de la orientación aristotélica de su pensamiento. La segunda concebiría el arte como el ejercicio de una virtud por medio de la práctica (poiesis). Ahora bien, como se desprende de la lectura del capítulo de la obra de Beuchot que hemos citado, el autor se centra en la primera parte puesto que las referencias a la segunda en la obra del Aquinate son mucho más escasas y se basan sobre todo en una lectura indirecta de la teoría tomasiana de las virtudes contenida en la Secunda Pars de la Suma

46 Cf. Jacques Maritain, Art et scolastique, Paris, Rouart et Fils, 1920, 50-51.

47 Puede verse, entre otros, Umberto Eco, Il problema estetico in San Tomasso, Milan, Bompiani, 1970. En español ha tenido gran repercusión Arte y Belleza en la Estética Medieval, Barcelona, Lumen, 1997.

48 Cf. Mauricio Beuchot, Introducción al estudio de Santo Tomas de Aquino, Salamanca, San Esteban, 2003, 243. 
Teológica. ${ }^{49}$ La teoría del arte de Santo Tomás (y esta es una de sus grandes limitaciones) se mueve en esquemas que no atienden a fenómenos como la creatividad y no se vincula con sus reflexiones sobre la belleza. ${ }^{50}$ La belleza es para Santo Tomás algo mucho más amplio. El arte puede ser bello, sin duda, pero la belleza es algo más.

A la hora de abordar las fuentes del pensamiento tomasiano ${ }^{51}$ sobre la belleza conviene hacer una precisión. ${ }^{22}$ Las referencias a la palabra pulchrum y derivados son abundantes en la obra de Santo Tomás, pero pocas de esas referencias son de utilidad a la hora de construir la concepción tomasiana de la belleza. El Comentario a las Sentencias, es una obra de juventud que depende mucho del pensamiento de Pedro Lombardo. Por otro lado, en el comentario a De Divinis Nominibus Santo Tomás se dedica a comentar al Pseudo Dionisio de forma que su pensamiento propio queda más velado que expuesto. Por ello conviene que acudamos a los dos textos esenciales de la Summa Theologiae en los que el de Aquino trata sobre la belleza.

\subsubsection{ST I, q. 39 art. $8:{ }^{53}$ La belleza de las cosas creadas}

Ad pulchritudinem tria requiruntur: primo quidem integritas sive perfectio, quae enim diminuta sunt, hoc ipso turpia sunt.

Et debita proportio sive consonantia. Et iterum claritas, unde quae habent colorem nitidum, pulchra esse dicuntur.
[...] para la belleza se requiere lo siguiente: Primero, integridad o perfección, pues lo inacabado, por ser inacabado, es feo. También se requiere la debida proporción o armonía. Por último, se precisa la claridad, de ahí que lo que tiene nitidez de color sea llamado bello.

En un obiter dicta, tratando complejos aspectos de teología trinitaria (la cuestión 39 se centra en la relación entre las personas trinitarias y su esencia), Santo Tomás nos da esta definición de belleza que sorprende por varias razones. La más importante es la ausencia de referencia al ser divino del que participan las cosas. Santo Tomás, que desarrolló como nadie la noción de participación en su metafísica, no la incluye en esta descripción de la belleza. La segunda es la impronta agustiniana. En efecto, en las condiciones que

49 No nos podemos detener en desgranar la teoría del arte de Santo Tomás. Baste decir que, además de la relación con las virtudes que hemos señalado, es curiosa la vinculación que hace del arte con el juego en ST II-II q.168 a.3, en la misma línea que sigue Aristóteles. Cf. Juan Plazaola, Introducción a la Estética, Bilbao, Deusto, 2009³, 66.

50 Cf. Plazaola, Introducción a la Estética, 67.

51 Distinguimos entre "tomasiano" como referente al pensamiento de Santo Tomás, y "tomista" como aquella escuela de pensamiento que deriva del pensamiento de Santo Tomás.

52 Seguimos aquí a Pascal DasseleER, "Esthétique «thomiste» ou esthétique «thomasienne»?", Revue Philosophique de Louvain 97/2 (1999) 312-335.

53 Tomamos la traducción española de Santo Tomás De Aquino, Suma de Teología, vol. 1, Madrid, BAC, 2001, 389. 
Santo Tomás establece para la belleza de las cosas creadas resuena la exigencia de orden y proporción, del logos interno del que ya hemos hablado y que aparece en San Agustín y, al menos indirectamente, en el Pseudo-Dionisio. Para que algo pueda ser bello tiene que poseer una disposición formal específica que permita que esa belleza sea captada por los sentidos. Estamos pues en el plano de la belleza formal, que debe reunir ciertas condiciones.

¿Cuáles son esas condiciones de lo bello? Santo Tomás enumera tres: Integritas, proportio y claritas. La primera hace referencia a la plenitud o perfección de la cosa. En la óptica de la filosofía aristotélica, la dinámica del paso de la potencia al acto perfecciona al ente, que se realiza en su plenitud perfeccionándose. Así, algo bello es algo pleno, realizado en su esencia, lo que aísla esta condición de otros supuestos metafísicos y la refiere solo a sus propias características.

Por su parte, la proportio es el logos interno al que ya hemos hecho referencia. En otros pasos de la Summa, ${ }^{54}$ Santo Tomás utiliza esta misma expresión para referirse a la proporción aritmética, por lo que podemos interpretar la proportio como el orden al que se refería San Agustín al hablar de la música. Finalmente, la claritas es quizás el concepto más complejo de exponer. Con Dasselleer ${ }^{55}$ podemos entender la claritas como la "manifestabilidad" de la que ya hablamos en páginas anteriores. Esta condición, que sería la más específica de las cosas bellas, es la que vincula un concepto puramente formal de belleza como este con la metafísica que en el fondo subyace a esta definición.

Esta última afirmación puede sorprender. ¿No estamos describiendo a Santo Tomás en la línea de los que conciben la belleza desde un punto de vista formal y no metafísico? Ciertamente es así y a la definición que estamos analizando nos remitimos. Pero mal describiríamos la postura de Santo Tomás si afirmáramos que la definición de Santo Tomás de belleza no obedece a una metafísica. La metafísica de la belleza ontologizada que hemos descrito en la escuela franciscana sigue resonando en el pensamiento del de Aquino, aunque con menor intensidad. Santo Tomás sintetiza y armoniza las dos concepciones que hemos visto hasta ahora: belleza ontológica y belleza formal. ¿Cómo? Partiendo de las características que se aparecen a los sentidos (integridad, proporción, claridad) y de lo que ello provoca al que lo contempla, Santo Tomás se eleva hacia una consideración más abstracta de la belleza en su relación con el bien, pero sobre todo con la verdad. Lo veremos en el siguiente epígrafe al comentar el segundo texto clave de la Summa Theologiae.

\footnotetext{
54 Cf. ST II/II q. 61, a.2, c.

55 Cf. DasseleER, “Esthétique «thomiste»”, 319.
} 


\subsubsection{ST I, q. 5, a. 4, ad.1.56 la belleza metafísica}

Pulchrum autem respicit vim cognoscitivam, pulchra enim dicuntur quae visa placent. Unde pulchrum in debita proportione consistit, quia sensus delectatur in rebus debite proportionatis, sicut in sibi similibus; nam et sensus ratio quaedam est, et omnis virtus cognoscitiva. Et quia cognitio fit per assimilationem, similitudo autem respicit formam, pulchrum proprie pertinet ad rationem causae formalis.
Lo bello, por su parte, va referido al entendimiento, ya que se llama bello a lo que agrada a la vista. De ahí que lo bello consista en una adecuada proporción, porque el sentido se deleita en las cosas bien proporcionadas como semejantes a sí, ya que el sentido, como facultad cognoscitiva, es un cierto entendimiento. Y como quiera que el conocimiento se hace por asimilación, y la semejanza va referida a la forma, lo bello pertenece propiamente a la razón de causa formal.

Si el texto anterior nos daba las condiciones para que algo pueda ser considerado bello, este texto nos presenta la percepción de lo bello, sus efectos sobre el observador y su naturaleza epistemológica. Es quizás el texto más innovador del de Aquino en relación con la belleza, por lo que merece un comentario detallado. Destacamos tres aspectos:

I. Pulchrum autem respicit vim cognoscitivam: esta es una idea nueva en relación con lo que hemos estado viendo. Hasta ahora, los autores que hablaban de la belleza no hicieron mención del potencial epistemológico de la belleza de esta forma. Es verdad que siguiendo a Platón muchos de los autores hablaron de la belleza como un camino de acceso a realidades superiores, pero ninguno acentuó como Santo Tomás la idea de la belleza como una forma de conocimiento asociada a los sentidos. Para un platónico la expresión sensus ratio quaedam est es un difícil de admitir, pues el verdadero conocimiento siempre es conocimiento de ideas. Santo Tomás como buen aristotélico pone el inicio del proceso cognoscitivo en los sentidos, y por tanto la belleza, que es algo que afecta primordialmente a los sentidos (algo también novedoso) tiene, como ya hemos dicho, potencial epistemológico. Comienza aquí la ruptura de la identificación entre Bien y Belleza, tan cara al platonismo, y un acercamiento de la belleza a lo sensible, y en consecuencia a lo epistemológico, lo que llevará como veremos a acercar los conceptos de Belleza y Verdad.

II. Pulchra enim dicuntur quae visa placent: la definición clásica de los efectos de la belleza: la delectación en lo bello, la complacencia en la contemplación. Un concepto que tendrá una vida muy prolongada en la filosofía del arte a partir de la Ilustración.

III. Unde pulchrum in debita proportione consistit: aquí conecta Santo Tomás esta exposición de los efectos e implicaciones de la belleza con la

56 Cf. Tomás de Aquino, Suma de Teología, vol. 1, Madrid, BAC, 2001, 131. 
descripción de las condiciones para que algo sea bello que ya vimos en el epígrafe anterior.

Sin entrar en las complejidades de la teoría del conocimiento tomasiana, vemos de forma clara que ante lo bello las potencias del alma se activan y se inicia una forma de conocimiento que además provoca delectación. Pero como se puede comprobar, seguimos en el plano de lo sensible. En los dos textos sobre la belleza, Santo Tomás no se ha elevado en ningún momento a consideraciones metafísicas. En este último texto, la explicación sobre los efectos de la belleza se hace en el contexto de una cuestión destinada justamente a diferenciar el bien de la belleza. El bien, dice Tomás tiene razón de causa final, es decir, que mueve atrayendo, impulsando hacia un fin. La belleza, sin embargo, tiene razón de causa formal, es decir, se fundamenta en una determinada configuración de la forma, de la manifestación del logos interno que puede ser conocido (dimensión epistemológica de la belleza). Sin embargo, la afirmación que hace en ese mismo artículo de que"lo bello y el bien son lo mismo porque se fundamentan en lo mismo, la forma [...] pero difieren en la razón" ha llevado a muchos intérpretes a entender la belleza como un trascendental del ser. ${ }^{57}$

Nosotros no vamos a entrar en esa cuestión por ser compleja y exceder los límites de este estudio. Pero es importante destacar que la doctrina de los trascendentales y la incorporación de la belleza al mismo (según algunos) se sitúan en un plano metafísico que correspondería a lo que en la primera parte de este estudio hemos llamado belleza ontológica, es decir, belleza que corresponde al ser por el mero hecho de ser y que se halla en íntima unión con uno de los trascendentales clásicos, el Bien. Pero además del Bien, quizás una de las aportaciones más singulares del pensamiento del Aquinate sobre la Belleza es su unión con otro de los trascendentales: laVerdad. En efecto, en su exhaustivo estudio sobre los trascendentales en Santo Tomás, Jan A. Aersten (que niega la trascendentalidad de la belleza) afirma:

Tomás modifica la tesis de Dionisio sobre la identidad, de tal modo que la belleza se ve como lo que añade algo conceptualmente al bien. No hemos profundizado más en la sustancia de esta adición ni en el significado de esta modifica-

57 No podemos entrar en la historia de los trascendentales por la limitada extensión de este estudio. Baste decir que es una doctrina que se va a desarrollar desde la Summa de Bono de Felipe el Canciller fechada entre 1225 y 1228 hasta las Disputaciones Metafísicas de Suarez (1597) y que va a sintetizarse en afirmar que el ente, por el mero hecho de ser, es uno, verdadero y bueno (unum, verum el bonum). Esta enumeración aparecerá ya en De Veritate de Santo Tomás cuando este afirme, casi de pasada: sed ens, unum, verum et bonum secundum rationem suam habent quod sint unum secundum rem [...] (q1. a.1 in fine). 
ción. Según Tomás, la belleza añade al bien una relación a la potencia cognoscitiva. Lo que es nuevo en el pensamiento medieval sobre la belleza, comparado con el pensamiento griego, es este énfasis en la relación de la belleza con el conocimiento (cognitio, apprehensio). El énfasis en el aspecto cognoscitivo lleva a un cambio de lugar de la belleza, a saber, en la dirección de la verdad. ${ }^{58}$

Por tanto, como decíamos al final del apartado anterior, no es que Santo Tomás excluya radicalmente de su metafísica las consideraciones de la belleza. Simplemente no pone el acento en ella, dándola por supuesto. Eso sí, como de los textos se deduce, no llega a los extremos de la Summa Fratris Alexandri y de la escuela franciscana.

Por ello se puede decir que Santo Tomás es, como en otros muchos aspectos, un autor de síntesis. Por un lado, en su metafísica asume la tradición de la belleza ontológica heredada de la Biblia y de autores como el Pseudo-Dionisio en tanto en cuanto vincula a la belleza con el ser a través del Bien. Sin embargo esto lo hace de forma implícita, destacando en sus escritos de forma más desarrollada la segunda línea de pensamiento que hemos descrito: la belleza formal o belleza como logos interno. Al armonizar ambas líneas, aparece una concepción de belleza mucho más omnicomprensiva y que evita los excesos de las dos posturas. Así, no se llega al extremo de extender la consideración de bello hasta a las cosas monstruosas, como hacía Considerans, ni se llega a desvincular la belleza del ser dejándola como una mera cualidad formal.

\subsubsection{La belleza en Santo Tomás de Aquino y su posteridad filosófica}

Una vez que hemos expuesto el fragmentario y complejo pensamiento de Tomás de Aquino sobre la belleza estamos en disposición de reconstruir el concepto de belleza que maneja Santo Tomás, de tal forma que podamos apreciar su importancia en la reflexión estética posterior y en el camino hacia la autonomía del arte.

En primer lugar, la belleza es una "propiedad" (usamos este término con mucha cautela) de las cosas sensibles que reúnen ciertas condiciones: integritas, proportio, claritas. Estos aspectos son los que constituyen el logos interno que supone la belleza de las cosas y que es aprehensible por los sentidos. A partir de este nivel sensible, la percepción de la belleza produce delectación en quien la contempla y su aprehensión tiene que ver, en cierto modo, con una forma de conocimiento.

58 Jan A. Aertsen, La Filosofía Medieval y los Trascendentales: un estudio sobre Santo Tomás de Aquino, Pamplona, Eunsa, 2003, 344-343. 
Ahora bien, este conocimiento, ¿de qué clase es? Santo Tomás no lo explica y quedan fuera de los objetivos de nuestro estudio las complejas cuestiones epistemológicas que esto plantea. Sin embargo, de acuerdo con la metafísica de Santo Tomás, el conocimiento que inicia la belleza tiene que ver con la belleza que tienen los seres por el hecho de ser entes y por tanto participar de los universales, entre los que Santo Tomás vincula especialmente la belleza con la Verdad y el Bien.

Así, podríamos decir que la Belleza hace cognoscible al Bien, en tanto que añade algo al Bien: su "manifestabilidad" a través del logos interno. Así, el círculo de los trascendentales se cerraría con la belleza, que si no es un trascendental bien podría ser la "corona del ser", que a través de las cosas bellas y su inteligibilidad permite el acceso a la entraña de la realidad.

Esta sería, en apretada síntesis, nuestra reconstrucción del pensamiento de Santo Tomás sobre la belleza. Una noción sintética de dos tradiciones distintas y con muchas complejidades en la que no podemos entrar. Asimismo, una noción fecunda en lo que a su posteridad se refiere. La vinculación entre belleza y conocimiento, entre percepción de la belleza sensible y la inteligibilidad de lo real (entre Belleza yVerdad) evoca el juicio estético kantiano. Así, afirma R. Bayer: "la estética de Santo Tomas comienza por ser una estética sensualista y empírica con el hedonismo de la vista y se desplaza después, como la de Kant, a una estética del juicio para establecer la preeminencia del juicio racional." ${ }^{\prime 59}$

En ese mismo sentido queremos apuntar a una dirección del pensamiento sobre la belleza (y, a partir de aquí, sobre el arte) que creemos halla sus raíces en Santo Tomás. Como ya hemos dicho, Santo Tomás parte de los datos de la sensibilidad para hablar de la belleza, para luego elevarse a cuestiones metafísicas. Así, y como vimos en Suger, el arte como expresión de cosas bellas aparece subordinado a una concepción metafísica que incluye a Dios y a la realidad como manifestación de Dios. En ese sentido, cualquier consideración que hiciera Santo Tomás sobre las artes y las cosas bellas no podría prescindir de los presupuestos metafísicos. Ahora podríamos hacernos la siguiente pregunta: ¿qué pasaría si desaparecieran esos presupuestos metafísicos?

Es lo que va a suceder con el Renacimiento y la Modernidad. La ruptura de la ecumene cristiana y la desaparición del paradigma filosófico medieval con el giro antropológico hará que la metafísica elaborada por la escolástica entre en una grave crisis y que los grandes pensadores elaboren sistemas que prescindan de sus postulados básicos. Por ello, la

59 Raymond BAYER, Historia de la Estética, México, FCE, 1980, 89. 
naciente estética de la Modernidad va a olvidar las cuestiones planteadas por la metafísica clásica pero se va a quedar con el punto de partida de Santo Tomás: los datos de la sensibilidad y el componente epistemológico de la belleza, que santo Tomás había puesto de manifiesto.

$\mathrm{Al}$ poner el acento en la aprehensión sensible de la belleza, Santo Tomás está siendo más moderno de lo que se le suele atribuir y está abriendo camino a que la reflexión sobre el arte cobre autonomía frente a constricciones de tipo metafísico, partiendo de lo sensible, de lo que se manifiesta. Al diferenciar el Bien de la belleza y al establecer una vinculación entre belleza y Verdad o inteligibilidad Tomás se distanciaba de lo que hemos llamado belleza ontológica y abría la belleza formal a la epistemología, al conocimiento de lo bello y por lo bello. En suma, abría la puerta a una reflexión sobre lo bello a partir de su manifestación sensible, es decir, a la estética. Por evocar un célebre verso de Keats: Truth is beauty, Beauty is truth.

\section{EPÍLOGO: ANACRÓNICAS REFLEXIONES SOBRE LA ACTUALIDAD DE LO INACTUAL}

Cuando concluimos estas páginas podría suscitarse una cuestión: y todo esto, ¿para qué? ¿es simplemente una investigación sobre los orígenes de la reflexión estética? ¿o tiene algún tipo de validez para nuestros días más allá de la erudición? A nuestro juicio, algo se puede aprovechar de estas consideraciones medievales sobre la belleza.

En primer lugar, nos gustaría llamar la atención sobre lo "contracultural", es decir, opuesto a los valores imperantes, de muchas de estas ideas hoy en día. Hoy, cuando el paradigma del conocimiento es el que proporcionan las ciencias experimentales, el susceptible de formalización, la idea de que las cosas que se nos presentan a la percepción (y entre ellas las obras de arte) puedan tener un logos interno al que llamamos belleza y que esta belleza sea un modo de conocimiento, de acceso "no racional" a la realidad, es profundamente revolucionaria.

En un mundo desencantado - por usar la expresión de MaxWebercomo el actual, que la belleza sea un modo de conocimiento abre la posibilidad de replantear la racionalidad tal y como se ha entendido a partir de la Modernidad. Nos situaríamos aquí, aunque desde otra perspectiva, en la línea de la crítica de la Modernidad que iniciaron Horkheimer y Adorno (aunque ciertamente Adorno no se sentiría cómodo ante reflexiones como estas). Una razón no destronada, sino ampliada en miras a una concepción integral del hombre. 
En segundo lugar, bien es sabido que los distintos acontecimientos del siglo XX han imprimido un sesgo pesimista y negativo a la reflexión estética. Acabamos de citar a Adorno, que tuvo muy presente el Holocausto a la hora de pensar el rol del arte en la sociedad moderna. Pues bien, en un mundo como el actual, donde la barbarie y la irracionalidad crecen, las fronteras que una vez se creyeron derribadas vuelven a alzarse y los excluidos son cada vez más excluidos, ¿no podría servir como un rayo de esperanza la belleza tal y como la entendieron los pensadores medievales?

En ese sentido, resulta interesante conectar esto con la noción de autonomía modal que maneja el prof. Jordi Claramonte en el libro Estética Modal. Para él, "la autonomía — como hemos empezado sosteniendo - tiene algo que ver con la capacidad contagiosa e instituyente para organizar nuestras propias vidas" ${ }^{60}$ Así, al insistir sobre el potencial transformador del arte y en su despliegue social se pone el acento en la importancia del arte en la configuración del mundo. Pues bien, tesis como las de los autores medievales que hemos reseñado nos parecen con un inmenso potencial.

Desde ese punto de vista, la belleza como esplendor de la verdad de la realidad de la que participan los seres, defendida por muchos en la Edad Media, es hoy un pensamiento revolucionario y casi peligroso. Donde abunda el odio y la exclusión podría sobreabundar aquello que la belleza suscita: el amor con su potencial de transformación social. Como es obvio, para quien hoy comparta la fe cristiana (como quien esto escribe) no habrá problema en suscribir esto, pues como hemos visto la creencia en un Dios personal, creador y providente conlleva la bondad y belleza de todas las cosas. Pero hay algo más allá de esto. Si el arte tiene ese algo que nos lleva de la contemplación a la acción, ${ }^{61}$ la belleza tiene un potencial contagioso que no se queda en el individuo, sino que tiende a ser diffusioum sui.

Esta es una idea seductora sin duda pero que tenemos que contrastar con lo que hemos expuesto en las páginas anteriores. El principal problema que presenta la visión ontológica de la belleza (a la que hemos dedicado la primera parte del estudio) es justamente el de anular la reflexión estética y privar de su especificidad al objeto estético. Si todo es belleza por el mero hecho de ser, ¿qué sería del arte?Ya hemos visto en la reflexión de Suger de Saint-Denis como entonces el arte queda reducido a su función anagógica, a un camino hacia la belleza del ser.

\footnotetext{
60 Cf. Jordi Claramonte Arrufat, Estética Modal, Libro Primero, Madrid, Tecnos, 2017, 18.

61 Cf. Claramonte Arrufat, Estética Modal, 18-19.
} 
Ahora bien, yendo más allá podría abrirse camino una reflexión sobre la belleza (y sobre el arte) que enfatice la participación de todas las cosas en ella en la línea de lo que sintetizó santo Tomás y que no privara de valor la reflexión estética en su potencial transformador. En efecto, aunando las dos líneas que hemos expuesto, Santo Tomás parte de la sensibilidad en su reflexión sobre la belleza. Ahora bien, esa visión no se queda ahí, sino que es capaz de ver en la belleza de las cosas sensibles un esplendor superior.

Frente a la visión ontológica defendida por el Pseudo-Dionisio, que devalúa la sensibilidad, base de la experiencia y reflexión estéticas, Santo Tomás parte de la sensibilidad que es capaz de percibir el logos interno, abriendo la puerta justamente a la experiencia estética propiamente dicha. Así, al invertir el proceso, Santo Tomás en cierto modo seculariza y des-ontologiza la experiencia sensible frente a un objeto estético. Por retomar (y justificar) el título de nuestro estudio, Santo Tomás permite el tránsito de la ontología al arte en sus consideraciones sobre la belleza.

Como hemos visto, son pocos los pensadores medievales que realizan de forma expresa este tránsito de la ontología al arte, es decir, de una metafísica concreta de la belleza a reflexionar sobre el arte, su esencia y sus funciones. Suger de Saint-Denis, con la función anagógica, o Hugo de San Víctor, son autores que han sacado de forma expresa las consecuencias para el arte de su metafísica. En ese sentido, a lo largo de nuestro estudio discurre una pregunta clave: ¿se puede hablar de belleza sin una metafísica previa? Ninguno de los autores que hemos estudiado prescindió de una determinada concepción del ser y de la realidad a la hora de reflexionar sobre la belleza, y de hecho algunos llevaron la belleza hasta el ámbito del ser (y por tanto de toda la realidad), alejando belleza y arte. Frente a esto, Santo Tomás es un exponente del acercamiento de estas dos categorías, no tanto en su teoría del arte, sino en su acercamiento de la belleza y la epistemología, de la belleza y lo sensible.

Así, Santo Tomás no obvia sus propias opciones metafísicas y encuadra su reflexión sobre la belleza en una cosmovisión cristiana. Pero su concepción nos parece un camino hacia las futuras reflexiones estéticas al partir de la sensibilidad y de la forma de lo percibido. No seríamos sinceros si hiciéramos de Santo Tomás un ilustrado avant la lettre, pero su puesto en la historia del pensamiento estético debe ser reivindicado.

Abundando en esta línea, y para concluir nos gustaría traer a colación una reflexión muy interesante de Paul Gilbert. En su obra Metafísica, la paciencia de ser, el autor abre la puerta a una consideración sobre la belleza que pensamos tendría una gran fecundidad en nuestro mundo, herido por la desesperación. Al hablar de la integritas de Tomás, dice: 
¿Qué es la integridad de un ente? Teóricamente, la presencia de todos sus elementos esenciales. Por ejemplo, es bello un cuerpo al que nada le falta. Pero a una belleza natural como una puesta de sol sobre una montaña nevada, ¿qué podría faltarle para que deje de ser bella? [...] Por otra parte, muchos existentes no son capaces de manifestar la totalidad de su definición; aunque no integren todos sus rasgos formales, no carecen de belleza. Por ejemplo, para quien tiene una vista clara y la inteligencia penetrante, una persona minusválida puede gozar de una belleza en la que no quieren creer nuestras culturas de producción industrial pero que sus parientes y amigos, en medio del sufrimiento, reconocen de vez en cuando. ${ }^{62}$

La cita nos invita a cambiar nuestra mirada sobre el mundo y sobre el arte, a ampliar nuestras aproximaciones, siempre parciales, a los fenómenos y a dejarnos seducir por ellos para luego transformar el mundo con la belleza percibida. Hay algo más de lo meramente aparente en la belleza que se nos presenta a los sentidos, aunque muchas veces no sea la belleza canónica que solemos identificar con este concepto. Descubrir ese logos interno de la realidad, su claritas en palabras de Santo Tomás, es algo para lo que el arte está especialmente dotado. Santo Tomás acercó la belleza a los sentidos y nosotros podemos tomar su invitación para buscar en las cosas bellas algo más que placer o deleite. En las cosas bellas hallamos la verdad de las cosas, una verdad que le debemos a todos los que nos rodean.

62 Gilbert, Metafísica, la paciencia del ser, 384. 